\title{
Detection of EML4-ALK fusion gene and features associated with EGFR mutations in Chinese patients with non-small-cell lung cancer
}

This article was published in the following Dove Press journal:

OncoTargets and Therapy

5 April 2016

Number of times this article has been viewed

\section{Miaomiao Wen \\ Xuejiao Wang \\ Ying Sun \\ Jinghua $X i a$ \\ Liangbo Fan \\ Hao Xing \\ Zhipei Zhang \\ Xiaofei Li}

Department of Thoracic Surgery, Tangdu Hospital, The Fourth Military Medical University, Xi'an, Shaanxi, People's Republic of China
Correspondence: Zhipei Zhang; Xiaofei Li Department of Thoracic Surgery, Tangdu Hospital, The Fourth Military Medical University, I Xinsi Road, Xi'an, 710038, Shaanxi, People's Republic of China Tel +86298477 7934 Email zzpzyy@fmmu.edu.cn; I_tdxw@I63.com
Purpose: Echinoderm microtubule-associated protein-like 4-anaplastic lymphoma kinase (EML4-ALK) and epidermal growth factor receptor (EGFR) define specific molecular subsets of lung cancer with distinct clinical features. We aimed at revealing the clinical features of EML4-ALK fusion gene and EGFR mutation in non-small-cell lung cancer (NSCLC).

Methods: We enrolled 694 Chinese patients with NSCLC for analysis. EML4-ALK fusion gene was analyzed by real-time polymerase chain reaction, and $E G F R$ mutations were analyzed by amplified refractory mutation system.

Results: Among the 694 patients, 60 (8.65\%) patients had EML4-ALK fusions. In continuity correction $\chi^{2}$ test analysis, EML4- $A L K$ fusion gene was correlated with sex, age, smoking status, and histology, but no significant association was observed between $E M L 4-A L K$ fusion gene and clinical stage. A total of 147 (21.18\%) patients had EGFR mutations. In concordance with previous reports, EGFR mutation was correlated with age, smoking status, histology, and clinical stage, whereas patient age was not significantly associated with EGFR mutation. Meanwhile, to our surprise, six $(0.86 \%)$ patients had coexisting EML4-ALK fusions and EGFR mutations.

Conclusion: $E M L 4-A L K$ fusion gene defines a new molecular subset in patients with NSCLC. Six patients who harbored both $E M L 4-A L K$ fusion genes and $E G F R$ mutations were identified in our study. The EGFR mutations and the EML4-ALK fusion genes are coexistent.

Keywords: NSCLC, EML4-ALK fusion gene, EGFR mutation, RT-PCR

\section{Introduction}

Lung cancer is one of the most common malignancies and is a leading cause of cancer-related deaths worldwide, and it is associated with a 5-year survival rate of less than $15 \%$. $^{1,2}$ Non-small-cell lung cancer (NSCLC) accounts for approximately $80 \%-85 \%$ of lung cancer. Although progress has been made in traditional surgery, chemotherapy, and radiotherapy for the treatment of advanced lung cancer, clinical outcomes are still considered unsatisfactory, and the median survival rates are still limited. ${ }^{3}$ In recent years, with the development of molecular biology and human genomics, people are paying growing attention to tumor pathogenesis; molecular targeted therapy with high specificity and little adverse reactions has become an important therapeutic modality for lung cancer; ${ }^{4}$ and people have achieved great success, especially in treating patients with NSCLC. A successful example is the identification of the epidermal growth factor receptor ( $E G F R$ ) mutation as a reliable, predictive biomarker for $E G F R$ tyrosine kinase inhibitors (TKIs) treatment. In patients carrying the EGFR mutation who have been previously untreated, EGFR-TKIs have been demonstrated to be superior to cytotoxic chemotherapy. ${ }^{5}$ 
A fusion protein between the echinoderm microtubuleassociated protein-like 4 (EML4) and the anaplastic lymphoma kinase (ALK) in NSCLC was first identified by Soda in 2007. ${ }^{6} E M L 4-A L K$ is a fusion gene, which represents a new molecular target. It has been reported that the incidence of $A L K$ rearrangement ranged from approximately 3\% to $13 \%$ in unselected or selected patients with NSCLC. ${ }^{7-10}$ The EML4-ALK translocation can result in constitutive $A L K$ kinase activity and represents an oncogenic addiction pathway in lung cancer. EML4-ALK possesses potent oncogenic activity both in vitro and in vivo, and the tumor can quickly fade after administration of ALK-TKIs. ${ }^{6,11}$ Crizotinib, a small-molecule ALK-TKI, showed significant benefit to patients with advanced NSCLC with EML4-ALK fusion in clinical trials and has been approved by the US Food and Drug Administration for these patients. ${ }^{12}$

The present study focuses on the relationship between $E M L 4-A L K$ fusion and $E G F R$ mutation. Previous studies proved that $E M L 4-A L K$ fusion gene and $E G F R$ mutation have largely been reported to be mutually exclusive. ${ }^{7,13,14}$ During the detection of EML4-ALK, patients with coexisting EML4-ALK fusion gene and $E G F R$ mutation have been reported in some clinical cases. ${ }^{15-17}$ Therefore, we should pay close attention to the coexisting type rates that occurred in our study. In this study, we analyzed the relationship between EML4-ALK fusion gene and $E G F R$ mutation. Meanwhile, we investigated the prevalence of two major mutations and their clinical characteristics in 694 unselected Chinese patients with NSCLC. These results can provide theoretical basis and important reference for individualized treatment in NSCLC.

\section{Materials and methods Patients}

Fresh tumor specimens were obtained from 694 consecutive Chinese patients with NSCLC who underwent surgery at the Department of Thoracic Surgery, Tangdu Hospital (Xi'an, Shaanxi, People's Republic of China) from March 2012 to September 2014. The study was approved by the Review Board of the Fourth Military Medical University. Written informed consent was obtained from each patient prior to testing.

\section{Clinical characteristics}

Medical records of all patients including age, sex, smoking status, histology, and clinical stage were acquired. All patients suffered from NSCLC for the first time, and none of them had received any neoadjuvant chemotherapy or radiotherapy before surgery. Tumor histology was classified according to the 3rd World Health Organization (WHO)/International
Association for the Study of Lung Cancer (IASLC) criteria. ${ }^{18}$ Tumor stages were determined using Version 7 of the IASCL (IASCL, Aurora, CO, USA). The histological subtypes of all patients were reassessed by at least two lung pathologists.

\section{EGFR mutation and EML4-ALK fusion gene analysis}

EGFR mutation detection: Genomic DNA was isolated and purified from fresh tumor specimens using TIANamp Genomic DNA Kit (Taingen Biotech, Beijing, People's Republic of China) according to the manufacturer's instructions. After that, EGFR mutations were analyzed using the principle of amplified refractory mutation system (ARMS) ${ }^{19}$ following the protocol of the AmoyDx EGFR Gene Mutation Detection Kit (Amoy Diagnostics, Haicang, Xiamen, People's Republic of China) and covering 29 EGFR mutation hotspots from exons 18 to 21 . The assay was carried out according to the manufacturer's instructions using the MX3005P (Stratagene, La Jolla, CA, USA) real-time polymerase chain reaction (RT-PCR) system. PCR was performed with initial denaturation at $95^{\circ} \mathrm{C}$ for 5 minutes, followed by 15 cycles of amplification (at $95^{\circ} \mathrm{C}$ for $25 \mathrm{~s}, 64^{\circ} \mathrm{C}$ for $20 \mathrm{~s}$, and $72^{\circ} \mathrm{C}$ for $20 \mathrm{~s}$ ) and a final denaturation followed by 31 cycles of amplification $\left(\right.$ at $93^{\circ} \mathrm{C}$ for $25 \mathrm{~s}, 60^{\circ} \mathrm{C}$ for $35 \mathrm{~s}$, and $72^{\circ} \mathrm{C}$ for $20 \mathrm{~s}$ ), and the FAM and HEX signals were collected at $60^{\circ} \mathrm{C}$. The results were analyzed according to the criteria defined by the manufacturer's instructions. Positive results were defined as $\mathrm{Ct}$ (sample) $-\mathrm{Ct}$ (control) $<\mathrm{Ct}$ (cut-off).

EML4-ALK fusion gene detection: Total RNAs were extracted from fresh cancer tissues using an E.Z.N.A Total RNA Kit I (OMEGA Bio-tek, Norcross, GA, USA) following the manufacturer's instructions. EML4-ALK fusion genes were detected by RT-PCR, following the protocol given in the AmoyDx EML4-ALK Fusion Gene Detection Kit (Amoy Diagnostics). The assay was carried out according to the manufacturer's instructions with the MX3005P (Stratagene) RT-PCR system. The PCR conditions consisted of initial denaturation at $95^{\circ} \mathrm{C}$ for 5 minutes, followed by 15 cycles of amplification (at $95^{\circ} \mathrm{C}$ for $25 \mathrm{~s}, 64^{\circ} \mathrm{C}$ for $20 \mathrm{~s}$, and $72^{\circ} \mathrm{C}$ for $20 \mathrm{~s}$ ) and final denaturation followed by 31 cycles of amplification (at $93^{\circ} \mathrm{C}$ for $25 \mathrm{~s}, 60^{\circ} \mathrm{C}$ for $35 \mathrm{~s}$, and $72^{\circ} \mathrm{C}$ for $20 \mathrm{~s}$ ), and the FAM signal was collected at $60^{\circ} \mathrm{C}$. The results were analyzed according to the criteria defined by the manufacturer's instructions. Positive results were defined as $\mathrm{Ct}$ (sample) $<30$.

\section{Statistical analyses}

Statistical analysis was performed using SPSS Version 16.0 Statistical Software (SPSS Inc., Chicago, IL, USA). The 
$\chi^{2}$ test or Fisher's exact test was used to assess the relationship between the presence of $E G F R$ mutation and clinical features as well as $E M L 4-A L K$ fusion gene and the clinical features. All $P$-values were based on a two-sided hypothesis, and the statistical significance was set at $P<0.05$ for all analyses.

\section{Results}

\section{Correlation between EML4-ALK fusion gene and clinicopathologic characteristics}

The clinical characteristics of these 694 patients are described in Table 1. EML4-ALK fusion genes were identified in 60 $(8.65 \%)$ of all cases. EML4-ALK fusion gene was correlated with age, sex, smoking status, and histology, but no significant association was observed between EML4-ALK fusion gene and clinical stage.

\section{The proportion of clinicopathologic characteristics in patients with EML4-ALK fusion genes}

Among the 60 patients with $E M L 4-A L K$ fusion gene, 41 $(68.33 \%)$ were of lower median age and 19 (31.67\%) were of higher median age; $32(53.33 \%)$ were male and 28 (46.67\%) were female; 34 (56.67\%) were never smokers

Table I Association of EML4-ALK fusion gene with clinicopathological characteristics

\begin{tabular}{|c|c|c|c|}
\hline Characteristics & Total $^{\mathbf{a}}$ & EML4-ALK fusion ${ }^{a}$ & $P$-value \\
\hline Total patients & 694 & 60 & \\
\hline Sex & & & 0.000 \\
\hline Male & $504(72.62)$ & $32(6.35)$ & \\
\hline Female & $190(27.38)$ & $28(14.74)$ & \\
\hline Age (years) & & & 0.002 \\
\hline$<60$ & 340 (48.99) & $4 \mid(12.06)$ & \\
\hline$\geq 60$ & $354(51.01)$ & $19(5.37)$ & \\
\hline Smoking history & & & 0.001 \\
\hline Never & $259(37.32)$ & $34(13.13)$ & \\
\hline Ever $^{\mathrm{b}}$ & $435(62.68)$ & $26(5.98)$ & \\
\hline Histology & & & 0.000 \\
\hline ADC & $315(45.38)$ & $42(13.33)$ & \\
\hline SCC & $255(36.74)$ & $8(3.14)$ & \\
\hline ADSQ & $68(9.8 I)$ & 7 (I0.29) & \\
\hline Other NSCLC ${ }^{c}$ & $56(8.07)$ & $3(5.36)$ & \\
\hline Clinical stage & & & 0.063 \\
\hline I & $208(29.97)$ & $14(6.73)$ & \\
\hline ॥ & $152(21.90)$ & $8(5.26)$ & \\
\hline III & $248(35.73)$ & $26(10.48)$ & \\
\hline IV & 86 (12.39) & $12(13.95)$ & \\
\hline
\end{tabular}

Notes: ${ }^{2}$ Values in parentheses indicate percentage. ${ }^{\mathrm{b}} \mathrm{A}$ person who smoked more than 100 cigarettes in his/her past history was defined as an ever smoker. 'Other types included sarcomatoid, large cell, and mucoepidermoid.

Abbreviations: EML4-ALK, echinoderm microtubule-associated protein-like 4-anaplastic lymphoma kinase; ADC, adenocarcinoma; SCC, squamous cell carcinoma; ADSQ, adenosquamous carcinoma; NSCLC, non-small-cell lung cancer. and $26(43.33 \%)$ were smokers; 14 (23.34\%) patients were in stage I, eight (13.33\%) were in stage II, $26(43.34 \%)$ were in stage III, and $12(20 \%)$ were in stage IV; according to the IASLC, $42(70 \%)$ were adenocarcinomas, eight (13.33\%) were squamous cell carcinomas, seven (11.67\%) were adenosquamous carcinomas, and three (5\%) were other specified carcinomas.

\section{Correlation between EGFR mutation and clinicopathologic characteristics}

As shown in Table 2, of the 694 patients, we identified 147 (21.18\%) patients who harbored $E G F R$ mutations. Clinical and pathological characteristics were analyzed for association with EGFR mutation. Sex, smoking status, histology, and clinical stage were associated with $E G F R$ mutation, but no significant association was found between $E G F R$ mutation and age.

\section{The proportion of clinicopathologic characteristics in patients with EGFR mutations}

Of the 147 patients with EGFR mutation, 77 (52.38\%) were of lower median age and $70(47.62 \%)$ were of higher median age; 64 (43.54\%) were male and 83 (56.46\%) were

Table 2 Association of EGFR mutation with clinicopathological characteristics

\begin{tabular}{|c|c|c|c|}
\hline Characteristics & Total $^{a}$ & EGFR mutation $^{\mathrm{a}}$ & $P$-value \\
\hline Total patients & 694 & $147(2 \mid .18)$ & \\
\hline Sex & & & 0.000 \\
\hline Male & $504(72.62)$ & $64(12.70)$ & \\
\hline Female & $190(27.38)$ & $83(43.68)$ & \\
\hline Age (years) & & & 0.355 \\
\hline$<60$ & $340(48.99)$ & $77(22.65)$ & \\
\hline$\geq 60$ & $354(51.01)$ & 70 (19.77) & \\
\hline Smoking history & & & 0.000 \\
\hline Never & $259(37.32)$ & $105(40.54)$ & \\
\hline Ever ${ }^{\mathrm{b}}$ & $435(62.68)$ & $39(8.97)$ & \\
\hline Histology & & & 0.000 \\
\hline ADC & $315(45.38)$ & $114(36.19)$ & \\
\hline SCC & $255(36.74)$ & II (4.3I) & \\
\hline ADSQ & $68(9.8 I)$ & $17(25)$ & \\
\hline Other NSCLCc & $56(8.07)$ & $5(8.93)$ & \\
\hline Clinical stage & & & 0.008 \\
\hline 1 & $208(29.97)$ & $52(25)$ & \\
\hline ॥ & $152(21.90)$ & $17(11.18)$ & \\
\hline III & $248(35.73)$ & $57(22.98)$ & \\
\hline IV & $86(12.39)$ & $21(24.42)$ & \\
\hline
\end{tabular}

Notes: ${ }^{a}$ Values in parentheses indicate percentage. ${ }^{b} \mathrm{~A}$ person who smoked more than 100 cigarettes in his/her past history was defined as an ever smoker. 'Other types included sarcomatoid, large cell, and mucoepidermoid.

Abbreviations: EGFR, epidermal growth factor receptor; ADC, adenocarcinoma; SCC, squamous cell carcinoma; ADSQ, adenosquamous carcinoma; NSCLC, nonsmall-cell lung cancer. 
female; 105 (71.43\%) were never smokers and 39 (28.57\%) were smokers; 52 (35.37\%) patients were in stage I, 17 (11.56\%) were in stage II, 57 (38.78\%) were in stage III, and $21(14.29 \%)$ were in stage IV; according to the IASLC, $114(77.55 \%)$ were adenocarcinomas, eleven (7.48\%) were squamous cell carcinomas, $17(11.56 \%)$ were adenosquamous carcinomas, and five (3.41\%) were other specified carcinomas; in addition, three cases exhibited double mutations in EGFR exons, including E(G719X; L861Q), E(G719X; S768I), and E(19-del; T790M).

\section{Characteristics in patients with NSCLC with EGFR/EML4-ALK coalterations}

Six patients $(0.86 \%)$ had coexistence of $E G F R$ mutation and $E M L 4-A L K$ fusion gene. Among the patients with coalterations, three (50\%) had adenocarcinomas, one (16.7\%) had mucoepidermoid carcinoma, and two (33.3\%) had sarcomatoid carcinomas; four (66.7\%) were male and two (33.3\%) were female; four $(66.7 \%)$ had a lower median age and two (33.3\%) had a higher median age; all the six (100\%) patients were never smokers; two (33.3\%) patients were in stage I, one $(16.7 \%)$ was in stage II, two $(33.3 \%)$ were in stage III, and one $(16.7 \%)$ was in stage IV. The clinical characteristics of the patients with coalterations are shown in Table 3. Typical results of patients with coalterations are shown in Figure 1.

\section{Discussion}

With the development of molecular medicine, the application of several molecular targeting drugs in lung cancer has garnered increased attention, and remarkable successes have been reported in several patients with NSCLC. Targeted biological therapies have led patients with advanced NSCLC to new therapeutic options. At present, EGFR-TKIs, such as gefitinib and erlotinib, have shown great efficacy in patients with NSCLC who have activation mutations in the EGFR gene. ${ }^{20,21}$ Recently, the discovery of the EML4-ALK fusion gene, which was first reported in NSCLC in 2007, represents a new molecular target. EML4-ALK fusion has been reported to suppress the growth of $E M L 4-A L K$-fusion-gene-positive cells. ${ }^{15,22}$ Thus, the $A L K$ inhibitors can be effective for patients with NSCLC whose tumors contain an EML4-ALK fusion gene. There are three usual methods for genetic detection - fluorescence in situ hybridization (FISH), RTPCR, and immunohistochemistry. ${ }^{23-25}$ We choose different methods according to different specimen types. RT-PCR is a highly sensitive and specific technique, and since fresh tumor samples after lung resection could be used in our study; we adopted RT-PCR as a detection method.

Previous studies reported that the incidence of EML4-ALK fusion gene varied from $3 \%$ to $5 \%$ in unselected populations, but the frequency is up to $13.5 \%$ in selected populations. ${ }^{16,26}$ The incidence of $E M L 4-A L K$ fusion gene in Chinese patients with NSCLC was approximately $2.6 \%-11.9 \%$, but the studies had some limitations, including smaller sample size. In our study, EML4-ALK fusion gene in unselected patients was detected by RT-PCR, and the incidence of EML4-ALK fusion gene was $8.65 \%(60 / 694)$. The clinical characteristics of $A L K$-positive or -negative patients were analyzed by $\chi^{2}$ testing, which showed significant differences in sex, age, smoking status, and histology. The proportion of EML4-ALK-positive patients seemed to be of younger age, light or never smokers, and had histology of adenocarcinomas. There are greater differences between the sexes in the patients who harbored EML4-ALK fusion gene. Shaw et $\mathrm{al}^{9}$ found that EML4-ALK fusion gene occurred more frequently in men, those of relatively young age, nonsmokers, and those with adenocarcinomas. ${ }^{9}$ However, in our study, the incidence of EML4-ALK fusion gene was significantly higher in women than in men. We suggest that the patients with NSCLC, both men and women, should be tested for $E M L 4-A L K$ fusion gene.

$E G F R$ mutation rate has obvious regional differences in NSCLC; it is reported that the EGFR-positive rate was found to be $30 \%$ in Asian patients ${ }^{27}$ but only $15 \%$ in American patients, ${ }^{28}$ and EGFR mutation was detected predominantly in Asian people, females, light or never smokers, and adenocarcinomas, which was consistent with previous reports. ${ }^{5,29}$ At present, the relationship between EGFR mutation and age is scarce; there is no clear explanation, and the mechanism still needs to be

Table 3 The clinical characteristics of six patients with EML4-ALK fusions and EGFR mutations

\begin{tabular}{llllllll}
\hline Patient ID & EGFR mutation & ALK fusion & Sex & Age (years) & Smoking status & Tumor histology & Stage \\
\hline I & E(I9-del) & Positive & Male & 46 & Never & Adenocarcinoma \\
2 & E(L858R) & Positive & Male & 24 & Never & Mucoepidermoid carcinoma \\
3 & E(I9-del) & Positive & Female & 64 & Never & Adenocarcinoma \\
4 & E(L86IQ) & Positive & Male & 67 & Never & Sarcomatoid carcinoma \\
5 & E(G7|9X) & Positive & Female & 47 & Never & Adenocarcinoma \\
6 & E(I9-del) & Positive & Male & 38 & Never & Sarcomatoid carcinoma & IIIB \\
\hline
\end{tabular}

Abbreviations: EML4-ALK, echinoderm microtubule-associated protein-like 4-anaplastic lymphoma kinase; EGFR, epidermal growth factor receptor. 

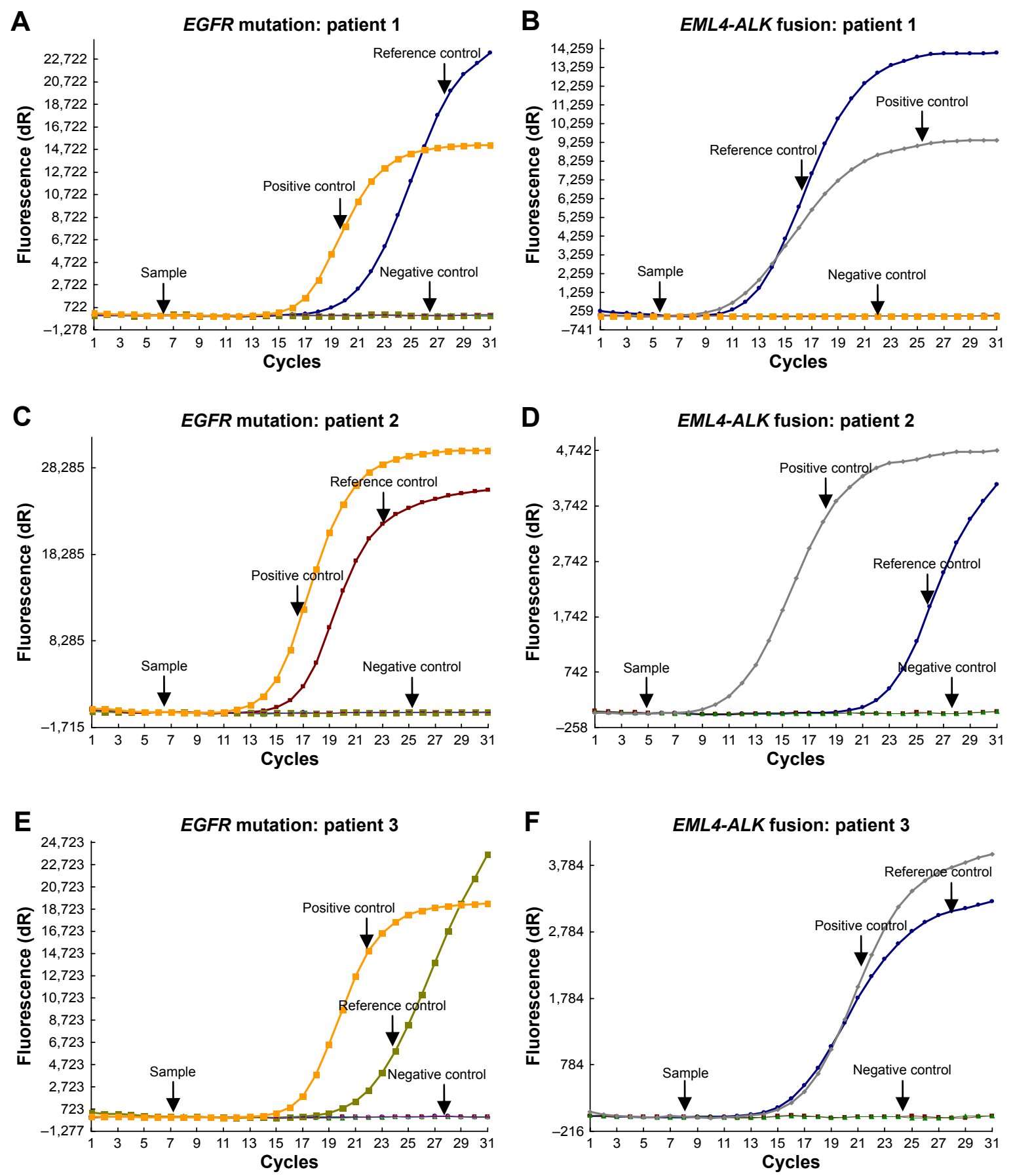

Figure I Representative results of patients with coalterations.

Notes: Amplification plots demonstrate the typical results of EGFR mutation and EML4-ALK fusion of patient I (A and B), patient 2 (C and $\mathbf{D})$, and patient 3 (E and $\mathbf{F})$. A, $\mathbf{C}$, and $\mathbf{E}$ demonstrate the results of exon 19 deletion mutation, exon 2I L858R point mutation, and exon 18 G7I9X point mutation, respectively. B, D, and $\mathbf{F}$ demonstrate the results of EML4-ALK fusion, respectively.

Abbreviations: EGFR, epidermal growth factor receptor; EML4-ALK, echinoderm microtubule-associated protein-like 4-anaplastic lymphoma kinase.

studied further. In this study, there was no statistical significance between $E G F R$ mutation and age.

EGFR mutation and EML4-ALK fusion have some similar clinical features, for example, these patients are light or never smokers and had histology of adenocarcinomas. Although previous reports have indicated that $E M L 4-A L K$ fusion gene and EGFR mutation were considered to be mutually exclusive in general, ${ }^{9,14,15,30}$ several studies have reported the coexistence of the EGFR mutation and EML4-ALK fusion gene, and the clinical features including Asian ethnicity, female, never or light smoking, adenocarcinomas, young patients with advanced cancer, and harboring EGFR mutations in 
exon 19 or exon $21 .^{15,31,32}$ In the present study, six patients had coexisting EML4-ALK fusion genes and EGFR mutations; further analysis revealed that of these six patients, four were male, three had adenocarcinomas, four were in relatively early stage of disease, four were of younger age, and $E G F R$ mutations were either exon 19 deletion mutations $(3 / 6)$, or exon 21 point mutations $(2 / 6)$, or exon 18 point mutation (1/6). In general, patients need to be tested for the presence of EML4-ALK fusion gene when the EGFR mutation is negative. Given the existence of double mutation, we can detect both EML4-ALK fusion and EGFR mutation to prevent missing $E M L 4-A L K$ fusion gene, and hence provide more choices to patients. EGFR-TKIs have become an indispensable and important modality for treating advanced NSCLC with an EGFR mutation. A series of driver genes of lung cancer have been identified, and $E M L 4-A L K$ fusion gene has become one of the research hotspots in recent years. However, because only few cases of coexistence of $E G F R$ mutation and $E M L 4-A L K$ fusion gene have been reported to date, and further research needs to be done. It still remains unclear as to how to introduce TKIs to patients who have coexisting EML4-ALK fusion gene and EGFR mutation. The appropriate treatment for coalternative patients should be further identified in the clinical trials.

\section{Conclusion}

We investigated the frequency of $E M L 4-A L K$ fusion gene and its association with clinicopathologic factors in 694 patients with NSCLC with identified EGFR mutation. Meanwhile, we found six patients had coexisting $E M L 4-A L K$ fusion genes and $E G F R$ mutations. The role of $E M L 4-A L K$ fusion gene as an oncogenic driver may be more important in NSCLC than what we expected. Furthermore, our study also revealed a strong association between $E M L 4-A L K$ fusion gene and sex, age, smoking status, and histology. Our data also suggested $E M L 4-A L K$ status should be investigated in unexplained cases of TKI-resistance of EGFR-mutated NSCLC. To better use targeted drugs, further study focusing on specific subgroups with EML4-ALK/EGFR coalterations should be performed in future.

\section{Acknowledgment}

The authors thank Ms Ruijuan Zhang, Pfizer Oncology (Beijing, People's Republic of China) for professional comments and references.

\section{Disclosure}

The authors report no conflicts of interest in this work.

\section{References}

1. Jemal A, Bray F, Center MM, Ferlay J, Ward E, Forman D. Global cancer statistics. CA Cancer J Clin. 2011;61(2):69-90.

2. Jemal A, Center MM, DeSantis C, Ward EM. Global patterns of cancer incidence and mortality rates and trends. Cancer Epidemiol Biomarkers Prev. 2010;19(8):1893-1907.

3. Schiller JH, Harrington D, Belani CP, et al. Comparison of four chemotherapy regimens for advanced non-small-cell lung cancer. $N$ Engl J Med. 2002;346(2):92-98.

4. Heist RS, Engelman JA. SnapShot: non-small cell lung cancer. Cancer Cell. 2012;21(3):448.e2.

5. Lynch TJ, Bell DW, Sordella R, et al. Activating mutations in the epidermal growth factor receptor underlying responsiveness of nonsmall-cell lung cancer to gefitinib. N Engl J Med. 2004;350(21): 2129-2139.

6. Soda M, Choi YL, Enomoto M, et al. Identification of the transforming EML4-ALK fusion gene in non-small-cell lung cancer. Nature. 2007;448(7153):561-566.

7. Horn L, Pao W. EML4-ALK: honing in on a new target in non-smallcell lung cancer. J Clin Oncol. 2009;27(26):4232-4235.

8. Sun Y, Ren Y, Fang Z, et al. Lung adenocarcinoma from East Asian never-smokers is a disease largely defined by targetable oncogenic mutant kinases. J Clin Oncol. 2010;28(30):4616-4620.

9. Shaw AT, Yeap BY, Mino-Kenudson M, et al. Clinical features and outcome of patients with non-small-cell lung cancer who harbor EML4ALK. J Clin Oncol. 2009;27(26):4247-4253.

10. Inamura $\mathrm{K}$, Takeuchi $\mathrm{K}$, Togashi $\mathrm{Y}$, et al. EML4-ALK fusion is linked to histological characteristics in a subset of lung cancers. $J$ Thorac Oncol. 2008;3(1):13-17.

11. Soda M, Takada S, Takeuchi K, et al. A mouse model for EML4ALK-positive lung cancer. Proc Natl Acad Sci U S A. 2008;105(50): 19893-19897.

12. Bergethon $\mathrm{K}$, Shaw AT, Ou SH, et al. ROS1 rearrangements define a unique molecular class of lung cancers. J Clin Oncol. 2012;30(8): 863-870.

13. Gainor JF, Varghese AM, Ou SH, et al. ALK rearrangements are mutually exclusive with mutations in EGFR or KRAS: an analysis of 1,683 patients with non-small cell lung cancer. Clin Cancer Res. 2013;19(15):4273-4281.

14. Sasaki T, Rodig SJ, Chirieac LR, et al. The biology and treatment of EML4-ALK non-small-cell lung cancer. Eur J Cancer. 2010;46(10): 1773-1780.

15. Koivunen JP, Mermel C, Zejnullahu K, et al. EML4-ALK fusion gene and efficacy of an ALK kinase inhibitor in lung cancer. Clin Cancer Res. 2008;14(13):4275-4283.

16. Zhang X, Zhang S, Yang X, et al. Fusion of EML4 and ALK is associated with development of lung adenocarcinomas lacking EGFR and KRAS mutations and is correlated with ALK expression. Mol Cancer. 2010;9:188.

17. Tiseo M, Gelsomino F, Boggiani D, Zhang J. EGFR and EML4-ALK gene mutations in NSCLC: a case report of erlotinib resistant patient with both concomitant mutations. Lung Cancer. 2011;71(2):241-243.

18. Beasley MB, Brambilla E, Travis WD. The 2004 World Health Organization classification of lung tumors. Semin Roentgenol. 2005; 40(2):90-97.

19. Liu J, Zhao R, Zhang J, Zhang J. ARMS for EGFR mutation analysis of cytologic and corresponding lung adenocarcinoma histologic specimens. J Cancer Res Clin Oncol. 2015;141(2):221-227.

20. Paez JG, Jänne PA, Lee JC, et al. EGFR mutations in lung cancer: correlation with clinical response to gefitinib therapy. Science. 2004; 304(5676):1497-1500.

21. Mok TS, Wu YL, Thongprasert S, et al. Gefitinib or carboplatinpaclitaxel in pulmonary adenocarcinoma. NEngl J Med. 2009;361(10): 947-957.

22. Choi YL, Takeuchi K, Soda M, et al. Identification of novel isoforms of the EML4-ALK transforming gene in non-small cell lung cancer. Cancer Res. 2008;68(13):4971-4976. 
23. Mino-Kenudson M, Chirieac LR, Law K, et al. A novel, highly sensitive antibody allows for the routine detection of ALK-rearranged lung adenocarcinomas by standard immunohistochemistry. Clin Cancer Res. 2010;16(5):1561-1571.

24. Boland JM, Erdogan S, Vasmatzis G, et al. Anaplastic lymphoma kinase imunoreactivity correlates with ALK gene rearrangement and transcriptional up-regulation in non-small cell lung carcinomas. Hum Pathol. 2009;40(8):1152-1158.

25. Rodig SJ, Mino-Kenudson M, Dacic S, et al. Unique clinicopathologic features characterize ALK-rearranged lung adenocarcinoma in the western population. Clin Cancer Res. 2009;15(16):5216-5223.

26. Vasikova A. EML4-ALK fusion gene in patients with lung carcinoma biology, diagnostics and targeted therapy. Klin Onkol. 2012;25(6): 434-439.

27. Wu YL, Zhong WZ, Li LY, et al. Epidermal growth factor receptor mutations and their correlation with gefitinib therapy in patients with non-small cell lung cancer: a meta-analysis based on updated individual patient data from six medical centers in mainland China. $J$ Thorac Oncol. 2007;2(5):430-439.
28. Keedy VL, Temin S, Somerfield MR, et al. American society of clinical oncology provisional clinical opinion: epidermal growth factor receptor (EGFR) mutation testing for patients with advanced non-small-cell lung cancer considering first-line EGFR tyrosine kinase inhibitor therapy. Clin Oncol. 2011;29(15):2121-2127.

29. Pao W, Miller V, Zakowski M, et al. EGF receptor gene mutations are common in lung cancer from "never smoker" and are associated with sensitivity of tumors to gefitinib and erlotinib. Proc Natl Acad Sci USA. 2004;101(36):13306-13311.

30. Inamura $\mathrm{K}$, Takeuchi $\mathrm{K}$, Togashi $\mathrm{Y}$, et al. EML4-ALK lung cancers are characterized by rare other mutations, a TTF-1 cell lineage, an acinar histology, and young onset. Mod Pathol. 2009;22(4):508-515.

31. Zhang XC, Zhang S, Yang XN, et al. Multiple EML4-ALK fusion transcripts and concurrent EGFR kinase mutation in Chinese non-small cell lung cancer. J Thorac Oncol. 2009;4(9):S549.

32. Zeng $\mathrm{Z}, \mathrm{Wu} \mathrm{Y}$. Research progress in non-small cell lung cancer with concomitant EML4-ALK fusion gene and EGFR gene mutation. Zhongguo Fei Ai Za Zhi. 2011;14(11):880-884. Chinese.
OncoTargets and Therapy

\section{Publish your work in this journal}

OncoTargets and Therapy is an international, peer-reviewed, open access journal focusing on the pathological basis of all cancers, potential targets for therapy and treatment protocols employed to improve the management of cancer patients. The journal also focuses on the impact of management programs and new therapeutic agents and protocols on

\section{Dovepress}

patient perspectives such as quality of life, adherence and satisfaction. The manuscript management system is completely online and includes a very quick and fair peer-review system, which is all easy to use. Visit http://www.dovepress.com/testimonials.php to read real quotes from published authors. 